\title{
Um Olhar Clínico para uma Justiça Cega: uma Análise do Discurso de Psicólogos do Sistema de Justiça
}

\author{
Danielle Cadan \\ Universidade Federal do Paraná, PR, Brasil.
}

\author{
Luciana Albanese \\ Universidade de São Paulo, SP, Brasil.
}

\begin{abstract}
Resumo: O presente artigo objetivou discutir a configuração da Psicologia jurídica, quando esta se direciona à descoberta de verdades no sistema de justiça. A perspectiva metodológica adotada para a realização da pesquisa foi a análise institucional do discurso. Os dados foram obtidos por meio de entrevistas semiestruturadas com seis psicólogos que atuam em órgãos componentes do sistema de justiça nos estados do Paraná e de Santa Catarina. Apareceram nos discursos dos participantes inúmeros embates quanto às práticas dos psicólogos junto ao direito, nas quais as demandas deste campo de atuação conflitavam com os discursos acerca da ética profissional da Psicologia. Os psicólogos mostraram não ter claramente a delimitação de sua clientela, o que os deixava, não raras vezes, em dúvidas sobre a quem deveriam servir, se ao sistema de justiça ou se à pessoa atendida. O objeto pelo qual a Psicologia jurídica reivindica exclusividade é a verdade e, para isso, disputa com o operador do direito sua posse. O psicólogo se imagina com capacidade de acessá-la e, para tal, utiliza-se do olhar da Psicologia clínica. Para surpresa das pesquisadoras, evidenciou-se que a verdade não era o que almejava somente o operador do direito, mas o psicólogo também. Sendo assim, falamos da configuração da Psicologia jurídica como uma prática que, por meio do olhar clínico do psicólogo, instrumentaliza com a verdade um sistema de justiça cego.
\end{abstract}

Palavras-chave:Verdade, Sistema de Justiça, Psicologia Jurídica, Análise Institucional do Discurso.

\section{A Clinical View of a Blind Justice: an Analysis of the Discourse of Psychologists from the Justice System}

\begin{abstract}
This article aims to discuss the configuration of legal psychology whenever its goal is to discover the truth in justice systems. The methodology adopted in the research was the analysis of the institutional discourse. Data was obtained through semi-structured interviews with six psychologists who worked in bodies of the Justice system in the states of Paraná and Santa Catarina, Brazil. Several clashes over the practices of legal psychologists appeared in the participants' discourses, revealing that these practices often conflict with the professional ethics of Psychology. The psychologists stated that they often had no clarity as to whom they should serve, whether the Justice system or the person in question. The object to which juridical psychology claims exclusivity is the truth, and this often leads to disputes about its possession with law practitioners. Psychologists imagine themselves capable of discovering the truth through clinical psychology. To the researchers' surprise, it became clear that the truth was not only what the law practitioner wanted, but also what psychologists wanted. Therefore, we see the practice of legal psychology through a clinical approach as a tool to achieve a truly blind Justice system.
\end{abstract}

Keywords: Truth, Justice System, Legal Psychology, Institutional Discourse Analysis. 


\title{
Una Mirada Clínica para una Justicia Ciega: un Análisis del Discurso de Psicólogos del Sistema de Justicia
}

\begin{abstract}
Resumen: El presente artículo objetivó discutir la configuración de la Psicología jurídica, cuando ésta se dirige al descubrimiento de verdades en el sistema de Justicia. La perspectiva metodológica adoptada para la realización de la investigación fue el análisis institucional del discurso. Los datos fueron obtenidos por medio de entrevistas semiestructuradas con seis psicólogos que actúan en órganos componentes del sistema de justicia en los estados de Paraná y de Santa Catarina. Aparecieron en los discursos de los participantes innumerables embates en cuanto a las prácticas de los psicólogos junto al derecho, en los cuales las demandas de este campo de actuación estaban en conflicto con los discursos acerca de la ética profesional de la psicología. Los psicólogos mostraron no tener clara la delimitación de su clientela, lo que los dejaba, no raras veces, en dudas sobre quién deberían servir, si al sistema de justicia o si a la persona atendida.. El objeto por el cual la psicología jurídica reivindica exclusividad es la verdad y, para ello, disputa con el operador del derecho su posesión. El psicólogo se imagina con capacidad de acceder a ella y, para ello, se utiliza de la mirada de la psicología clínica. Para sorpresa de las investigadoras, se evidenció que la verdad no era lo que anhelaba solamente el operador del derecho, sino el psicólogo también. Siendo así, hablamos de la configuración de la psicología jurídica como una práctica que, por medio de la mirada clínica del psicólogo, instrumentaliza con la verdad un sistema de justicia ciego.
\end{abstract}

Palabras clave:Verdad, Sistema de Justicia, Psicología Juridica, Análisis Institucional del Discurso.

O tema abordado no presente artigo faz parte de uma pesquisa que buscou identificar no discurso de psicólogos que atuam no sistema de justiça brasileiro como suas práticas são configuradas, investigando princípios e pressupostos que norteiam tais atuações. O objeto tomado para análise, portanto, são os discursos desses psicólogos e, neles, as imagens que se delineiam da Psicologia jurídica. Mais especificamente, para os propósitos deste texto, o recorte operado, decorrente da análise das entrevistas realizadas com os participantes da pesquisa, volta-se à recorrência com que tais profissionais apontaram em seus discursos uma ação profissional do psicólogo no sistema de justiça: a busca e a descoberta de pretensas verdades.

O termo sistema de justiça aqui será utilizado para designar o conjunto de atores responsáveis pela aplicação da lei em casos de conflitos de interesses que ensejam intervenção estatal, conforme usa-se comumente neste contexto, já que não foi encontrado, por estas pesquisadoras, um conceito técnico nas ciências jurídicas que o defina. Dentre outros, mas não somente, fazem parte do sistema de justiça brasileiro, o Poder Judiciário, o Ministério Público, a Defensoria Pública e as polícias judiciárias (Civil e Federal), sendo todos estes órgãos comandados por bacharéis em direito, costumeira- mente chamados operadores do direito, sejam juízes, promotores, delegados de polícia, defensores etc.

A elucidação de algo que estaria encoberto, e que a Psicologia, como ciência, poderia desvelar, faz parte dos primórdios do que seria o nascimento da Psicologia Jurídica. Brito (2012) indica que, no cenário mundial, no final do século XIX, numa época em que vigorava uma visão positivista de ciência, os métodos das ciências da natureza (originadas da biologia) eram os que deveriam ser seguidos. Neste contexto ocorreu o primeiro contato entre a Psicologia e o direito, fazendo surgir a Psicologia do testemunho. Conforme apontam historiadores, os laboratórios experimentais, dos quais Wundt foi pioneiro em 1879 na Alemanha, surgiram a partir de demandas da justiça. Neles deveriam ser realizados estudos sobre percepção, memória, sensações, entre outros temas relacionados à compreensão do testemunho, para o desenvolvimento de técnicas de aferição da fidedignidade do que se falava perante o sistema de justiça. Tal área objetivava a verificação da veracidade do relato da pessoa envolvida em um processo jurídico, lançando mão, principalmente, da utilização de testes, pois se esperava que assim fosse possível compreender os comportamentos que deveriam ser submetidos à ação jurídica, segundo descreve Altoé (2003). 
A Psicologia do testemunho, mesmo sua inauguração tendo acontecido no século retrasado, ainda é prática e tema de pesquisa e de desenvolvimento de instrumentos de diversos psicólogos, como as produções de Felix e Pergher (2010), Paulino (2009), Rovinski (2007a, 2011), Stein (2009), entre outros. Segundo Ambrosio (2010), a partir de métodos específicos e instrumentos próprios, a Psicologia se prestaria a atestar a veracidade do relato da testemunha no processo judicial. Assim, idealizando a justiça e o alcance de uma verdade, órgãos legislativos e judiciários incorporaram em seus procedimentos noções de outras áreas, tendo sido a Psicologia requisitada a participar com seus conhecimentos científicos. Neste contexto, configurou-se, e ainda se configura, o que chamamos hoje de Psicologia Jurídica.

As inquietações sobre a intervenção da Psicologia no campo do direito - mais precisamente no sistema de justiça -, as quais motivaram o presente estudo, tiveram início a partir da atuação de uma das pesquisadoras como psicóloga da polícia civil do estado de Santa Catarina. Este órgão, que faz parte do poder executivo, compõe o sistema de justiça brasileiro, uma vez que no contexto da persecução criminal é o responsável pela investigação, a qual é presidida por um operador do direito, isto é, pelo delegado de polícia judiciária. Tal atuação do psicólogo é demarcada por constantes tensões entre as normativas éticas que regulamentam a profissão do psicólogo pelo Conselho Federal de Psicologia (CFP) e as solicitações dos operadores do direito a este profissional, o que leva a diversos conflitos entre os dois campos de conhecimento e prática profissional: a Psicologia e o direito. Percebe-se que, com seus discursos naturalizados, ao reconhecerem seu modo de ser/fazer no sistema de justiça como sendo o único possível, os atores de ambas as áreas, muitas vezes, desconhecem outras formas de atuar. A repetição cotidiana das práticas, sem o questionamento de suas origens, culmina na naturalização do que se faz e, assim, no entendimento de que este seria o único modo de atuar, tanto para a Psicologia como para o direito, no sistema de justiça.

Nota-se, na prática desta pesquisadora, que os órgãos do sistema de justiça, não raras vezes, solicitam o engajamento do psicólogo para a elucidação de fatos, objetivando o alcance de uma pretensa verdade.
Em oposição, psicólogos, orientados pelo CFP, colocam-se contrários às práticas que suscitam tais objetivações. Este órgão preconiza que deve ser levada em conta a dinamicidade das relações sociais na elaboração dos documentos de caráter psicológico, uma vez que é preciso considerar que as questões de ordem psicológica - objetos de estudo do psicólogo - são determinadas pelos contextos histórico, social, econômico e político em que aparecem e, mais, elas são elementos que constituem o sujeito como tal, ou seja, são constitutivas do processo de subjetivação. Sendo assim, tendo o objeto de estudo do psicólogo um caráter dinâmico, este não deve ser entendido como definitivo e cristalizado. Portanto, não se pode falar sobre uma verdade objetiva acerca das relações sociais, conforme pode ser visto na Resolução CFP ${ }^{\circ}$ $007 / 2003$. Este é um dos diversos exemplos que poderiam ser aqui trazidos para ilustrar o campo de tensões existente na atuação do psicólogo jurídico.

Ao longo dos cinco anos de serviços prestados em quatro delegacias de polícia especializadas de diferentes cidades do estado de Santa Catarina ${ }^{1}$, tem-se observado que a demanda da instituição jurídica à Psicologia diz respeito a uma aspiração por respostas aos seus questionamentos, em que o psicólogo é convocado a contribuir na produção de provas durante as investigações policiais, das quais, por sua vez, o objetivo é a revelação de uma pretensa verdade sobre as ocorrências notificadas. Há a expectativa, por parte dos operadores do direito, de descoberta de fatos que estariam encobertos e, parece que, segundo o entendimento deles, a Psicologia possuiria as técnicas que poderiam auxiliar o sistema de justiça nesta sua empreitada. Por exemplo, diversas são as requisições a estes psicólogos para atestarem a veracidade de relatos de testemunhas de supostos crimes, ou seja, esperam que o profissional de Psicologia emita um laudo conclusivo sobre a ocorrência ou não do abuso sexual contra a criança, como acontece na prática cotidiana de muitos psicólogos da polícia civil. Assim, ao que parece, para o operador do direito, ao possuir instrumental específico para tanto, a ciência psicológica cumpriria a expectativa de corroborar a elucidação de um fato, nele evidenciando as suas verdades.

A perspectiva metodológica escolhida para esta pesquisa, dentre outras possíveis, a análise institucio-

${ }^{1}$ A polícia civil de Santa Catarina possui Delegacias de Proteção à Criança, ao Adolescente, à Mulher e ao Idoso (DPCAMI) em diversas cidades do estado. A maioria dos psicólogos da polícia civil estão lotados em tais repartições. O trabalho predominante destes profissionais é o atendimento de crianças. 
nal do discurso (AID), compreende a Psicologia como instituição do conhecimento e da prática profissional. Exercer a Psicologia, aqui, é produzir e reproduzir verdades (Guirado, 2010). Para melhor entender tal afirmativa, convém resgatar o que sua autora concebe como sendo discurso e instituição.

A instituição é definida, pela AID, segundo as ideias do sociólogo Guilhon Albuquerque, como sendo "um conjunto de relações sociais que se repetem e, nessa repetição, legitimam-se" (Guirado, 2010, p. 45). Apropriando-se de tal ideia, a AID utiliza esse conceito para se referir a práticas que já são naturais para o sujeito, cujas origens não são questionadas e as regras são compartilhadas naturalmente sem indagações sobre seus fundamentos. Assim, num movimento de reconhecimento dessas práticas como sendo as únicas possíveis e num desconhecimento de outras formas de fazê-las, conforme nos ensina Guirado (1997), a AID trabalha com a ideia da instituição das relações sociais que podem ser pensadas como práticas discursivas.

O conceito de discurso da AID é desenvolvido a partir da concepção foucaultiana de formação discursiva, tratando-se esta de "um conjunto de regras anônimas, históricas, sempre determinadas no tempo e no espaço, que definiram em uma época e para uma área social, econômica, geográfica ou linguística as condições de exercício da função enunciativa" (Foucault, 2005, p. 133). Com isso, Guirado (2010) propõe o discurso como ato, tendo ele a qualidade de determinar regras e lugares, organizando as relações sociais. Ao falar, o sujeito configura lugar, poder, sentido e subjetividade (Guirado, 1997), confirmando ou subvertendo lugares e expectativas e, com isso, organizando relações sociais. Ao falar, o indivíduo não expressa um pensamento, ele entra numa instituição que o domina, ou como diria Foucault, ele entra numa ordem discursiva (Guirado, 2000), cujas origens das regras são desconhecidas pelo falante. As práticas discursivas são atravessadas pelas relações de poder; poder aqui entendido como ação/regulação sobre/da conduta. Assim, ao dizer algo, o falante não apenas expressa uma ideia, mas atribui lugares (a si, a seu interlocutor e àquilo do que fala) e legitima práticas sociais.

A partir de tal perspectiva, a AID possibilitou ao pesquisador analisar de que modo vem configurando-se a Psicologia jurídica na atuação dos psicólogos que atuam no sistema de justiça e, ao mesmo tempo, como eles se constituem como psicólogos jurídicos, pois, sendo uma perspectiva minuciosa de leitura institucional, ela compreende a vida do sujeito nas instituições como matriz de toda a subjetividade, não existindo ela fora das instituições (Galvão, \& Serrano, 2007). Portanto, sendo este profissional um sujeito constituído em suas práticas discursivas, a análise de seus discursos é intrínseca à análise de sua constituição, ou melhor, ao modo como se reconhece, em seu dizer, psicólogo jurídico.

A temática da verdade é um dos recortes que, de forma ilustrativa, ao ser analisada, possibilitou responder ao objetivo investigado, afinal, apareceu com regularidade nos discursos analisados e, como tal, é pertinente à configuração da Psicologia jurídica como instituição e do psicólogo como agente que configura esta instituição em sua repetição de práticas cotidianas no sistema de justiça.

Situa-se a relevância deste artigo na necessidade de analisar como vem delineando-se a prática do psicólogo nesse campo, já que não está no seu setting tradicional, a clínica. Com isso é possível o fornecimento de subsídios aos profissionais que atuam na área jurídica, fazendo-os pensar sobre sua própria intervenção e vindo a refletir sobre as formas já cristalizadas que direcionam a prática dos psicólogos, mais especificamente sobre a produção de verdades. Guirado fala sobre os "cortes que fazem pensar" (2009, p. 331), ou seja, sobre aqueles momentos em que a intervenção ocorre sobre o que já está instituído e entendido como sendo a única forma possível, como sendo a verdade instituída. Por ser algo natural, há um desconhecimento de outras formas de atuar e um reconhecimento de uma única possibilidade. Assim, tais psicólogos se subjetivam nas práticas jurídicas, constituindo-se como sujeitos; sujeito este que reedita sua história de vínculos, de forma singular e, ao mesmo tempo, à medida que ocupa novos lugares, movimenta uma mudança no meio. Para ilustrar, a autora da AID usa a metáfora do sujeito-dobradiça, a qual diz respeito ao sujeito que se constitui singularmente como tal nas relações que estabelece nos variados contextos. Isto é, ela fala das condições institucionais em que o discurso é produzido e dos efeitos de subjetivação no psicólogo neste contexto. Neste estudo o contexto seria o sistema de justiça e a atuação do psicólogo nele.

Além disso, analisando-se que tipos de verdades estão sendo produzidas e reproduzidas no âmbito da Psicologia jurídica, espera-se suscitar reflexões sobre os modos como a Psicologia legitima-se como prática profissional no sistema de justiça. Também, almeja-se 
contribuir com produção de conhecimento para o direito quando se discute a relação dele com a Psicologia neste contexto. Ao possibilitar uma análise sobre a forma como estas disciplinas se comunicam e onde estão os limites e especificidades de cada uma delas, bem como suas expectativas, almeja-se poder contribuir com a construção da prática do psicólogo jurídico.

\section{As atuações dos psicólogos no sistema de justiça brasileiro}

O trabalho do psicólogo vem sendo frequentemente requisitado pelo sistema de justiça, seja pelos tribunais judiciais, pelos promotores de justiça, ou mesmo na fase pré-processual, durante o período investigativo, pela polícia judiciária. Tem-se demandado ao psicólogo, principalmente, temas envolvendo a infância, adolescência e conflitos familiares. Os documentos produzidos por esse profissional, muitas vezes, subsidiam relevantemente a decisão judicial. Nesse momento, realçam-se as maneiras como o psicólogo visualiza sua prática e o sentido que dá a ela, havendo vários entendimentos sobre a atuação frente à demanda jurídica. A discussão acerca do Depoimento sem Dano² ou, atualmente, chamado de Depoimento Especial, é um exemplo de tema debatido, e que gera animosidade entre os psicólogos, uma vez que alguns o reconhecem como prática da área psi, enquanto outros condenam veemente o uso de tal procedimento, descaracterizando-o como condizente com a atuação do psicólogo.

Diversos autores discutem o exercício de profissionais da Psicologia, no sistema de justiça, quando atuam na inquirição de crianças, por meio do Depoimento sem Dano, os quais, muitas vezes, na ânsia de responderem às demandas jurídicas, focam-se em fazer com que a criança fale, ou seja, que seu testemunho seja suficiente para a produção de provas para o sistema de justiça (Alves, \& Saraiva 2009; Brito, 2012; Froner, \& Ramires, 2008). Essa fala da criança, muitas vezes, torna-se decisiva na formalização da prova judicial, desconsiderando-se os possíveis prejuízos que tal depoimento pode acarretar a ela, já que ela não consegue apreender e nem projetar as consequências daquilo que diz (Arantes, 2009; Batista, \& Cadan, 2017; Froner, \& Ramires, 2008). Assim, discute-se se cabe à Psicologia adentrar nesta atuação de tomada de depoimento de crianças e adolescentes, prática esta, inclusive, que é contrária às propostas do CFP.

Para Alves e Saraiva (2009), algumas atividades no campo da Psicologia jurídica, como é o caso do Depoimento sem Dano, vêm produzindo uma determinada subjetividade: a criança vítima. A tarefa da Psicologia é de grande importância para o sistema de justiça na inquirição dessas crianças, o que pode compelir o psicólogo a "reificar um lugar de saber-poder" (Alves \& Saraiva, 2009, p. 102), já que há uma expectativa do direito de que o psicólogo trate as famílias 'disfuncionais" (aspas do autor) e as adeque ao padrão aceito de relacionamento. Ao sucumbir a tal missão, em nome de uma pretensa proteção da criança intitulada vítima, os limites para a atuação do psicólogo vão sendo extintos. Assim, segundo estes autores, o profissional de Psicologia toma para si o discurso jurídico do saber sobre o outro e, mais, sobre o que o outro precisa, a fim de protegê-lo. Arantes (2016) discorre sobre o princípio da proteção à criança, o qual é exaltado nas legislações sobre a infância, em detrimento aos princípios da liberdade e da participação. Deste modo, o psicólogo vem atuando como mais um dos técnicos do saber em prol de proteger crianças ao fazerem com prestem testemunhos com o fim de produção de provas para o direito e, consequentemente, para a punição de quem teria cometido um crime. Com isso, reforça-se uma lógica dualista entre inocente e culpado em uma trama no sistema de justiça, em que a criança é ocupa o papel de protagonista.

$\mathrm{Na}$ contramão dos críticos ao Depoimento sem Dano, Rovinski (2007a) faz a distinção entre a atuação do psicólogo nas áreas clínica e forense, colocando que o que as diferencia é o foco da avaliação: enquanto na avaliação forense o atendimento deve ser dirigido a eventos definidos pela demanda do judiciário, na atuação clínica objetiva-se a compreensão do mundo interior do paciente. A autora, e também psicóloga aposentada do Tribunal de Justiça do Rio Grande do Sul, aponta que esta diferenciação de foco tem sido um grande desafio aos psicólogos, por estarem familiarizados com a área terapêutica. Ela ressalta que a formação, durante a graduação, acaba por reforçar a visão clínica desses profissionais, levando-os a realizarem trabalhos interventivos com enfoque terapêutico. Assim, ela

${ }^{2}$ Projeto idealizado pelo Juiz de Direito José Antônio Daltoé Cezar, no ano de 2006, cujo modelo é utilizado no Juizado da Infância e da Juventude de Porto Alegre para inquirir crianças e adolescentes vítimas de abuso sexual. Tal procedimento está sendo recomendado como lei nacional (Alves \& Saraiva, 2009). 
destaca que, por esse motivo, os psicólogos, quando demandados a auxiliar o poder judiciário, enfrentam inúmeros conflitos éticos, especialmente no que diz respeito à confidencialidade das informações.

Como exemplo de embates fervorosos entre a Psicologia e as demandas do campo jurídico, temos algumas resoluções emitidas pelo CFP que, não muito tempo após suas publicações, foram anuladas pelo poder judiciário. Por meio desses documentos de orientação e regulamentação da prática do psicólogo, o conselho de classe buscou direcionar como o profissional deve atuar frente às solicitações advindas no contexto da justiça, inclusive esclarecendo que o seu descumprimento levaria à punição do psicólogo. Um caso recente ocorreu em 2007, quando, juntamente com o Ministério da Justiça e o Departamento Penitenciário Nacional (Depen), o CFP elaborou um manual chamado Diretrizes para a atuação e formação dos psicólogos do sistema prisional brasileiro, no qual propõe "a construção de uma outra forma de lidar com a criminalidade, pautada pela prevenção, educação, Justiça e responsabilização dos sujeitos e da sociedade" (Brasil, 2007, p. 11), e pincela sutilmente sua postura contrária à realização de exames criminológicos por estes profissionais. Já no ano de 2011, cria a Resolução CFP n ${ }^{\circ}$ 012/2011, em que regulamenta a atuação do psicólogo no âmbito das prisões e, aí, proíbe a prática do exame criminológico, podendo, no caso de solicitação judicial, realizar somente a perícia psicológica. Também, o psicólogo não poderia mais fazer "prognóstico criminológico de reincidência, a aferição de periculosidade e o estabelecimento de nexo causal a partir do binômio delito-delinquente" (2011, p. 4).

Em abril de 2015, a Resolução CFP n ${ }^{\circ}$ 012/2011, devido à ação do Ministério Público Federal contra o CFP e contra o Conselho Regional de Psicologia (CRP) da $7^{\text {a }}$ Região (RS), é suspensa em todo o Brasil. A partir de então, os psicólogos não poderiam mais ser punidos ao realizarem exames criminológicos. Ainda assim, o CFP continuou a emitir notas acerca de sua posição contrária, mesmo não havendo mais obrigação legal de cumprimento pelos psicólogos da referida resolução. Tal cenário gerou grande animosidade entre os próprios psicólogos; afinal, alguns se colocavam em concordância com o conselho de classe, enquanto outros posicionavam-se de acordo com a instância jurídica que pôs fim à citada resolução.
Anterior a esta resolução suspensa, no ano de 2012, a Resolução CFP nº 010/2010 também foi anulada, por oposição do Ministério Público Federal. Ela discorria sobre a forma como deveriam atuar os psicólogos na escuta de crianças e adolescentes, na rede de proteção e garantia de direitos, envolvidos em situação de violência. Nesta resolução, o Conselho de Psicologia, dentre outras atuações, findava a polêmica prática do depoimento sem dano. Segundo Alves e Saraiva (2009), este trabalho tinha como metodologia a utilização de um profissional de Psicologia que, em uma sala separada da sala de audiências, deveria inquirir a criança que constava como vítima de abuso sexual no procedimento judicial. Tal atendimento era transmitido por meio de aparelhos audiovisuais para os demais participantes, no ato da audiência, os quais poderiam transmitir perguntas para psicólogo fazer à criança. Para isso, o profissional de Psicologia estaria usando um ponto auditivo. Mesmo o conselho de classe sendo contrário a tal prática, porém, não dispondo mais de meios legais para proibição, diversos profissionais retomaram e/ou iniciaram o trabalho na realização deste depoimento.

Os Conselhos de Psicologia do Paraná (CRP-08) e de Santa Catarina (CRP-12), situados nos estados onde foram realizadas as entrevistas desta pesquisa, organizam, com frequência, eventos, sejam palestras, seminários, entre outros, nos quais reúnem profissionais do sistema de justiça. A partir disso, alguns documentos já foram emitidos, os quais expressam o posicionamento dos referidos conselhos de classe acerca da melhor atuação do psicólogo neste contexto.

Pontos de vista, sejam eles divergentes e/ou convergentes, entre os psicólogos e entre estes e os operadores do direito, dizem respeito às verdades produzidas no encontro entre os dois campos de conhecimento e prática profissional. A proximidade entre a Psicologia e o direito, por vezes, apresenta-se resistente, mas não somente, podendo elas serem áreas que, com suas particularidades, tornam-se complementares.

\section{Método}

A AID - como já dito, a perspectiva metodológica escolhida para esta pesquisa - permitiu às pesquisadoras um novo olhar sobre o que havia sido naturalizado nos discursos dos entrevistados, ou seja, sobre as verdades instituídas em suas práticas junto ao no sistema de justiça e, de que modo, tais verdades configuram a Psicologia jurídica. 


\section{Participantes}

Foram entrevistados seis psicólogos que atuam no sistema de justiça. Dentre eles, três psicólogos do Poder Judiciário (uma mulher e dois homens), uma psicóloga da Defensoria Pública, uma psicóloga do Ministério Público e um psicólogo da Polícia Civil. Omitiram-se ou alteraram-se dados que viessem a identificar os participantes, sendo que os nomes pelos quais os chamaremos neste estudo são fictícios. Os participantes atuam nos estados do Paraná e de Santa Catarina. Tais localidades foram selecionadas pela facilidade de acesso aos participantes, não tendo sido indicado aqui o estado em que atuava cada entrevistado devido à especificidade de suas funções, o que poderia acarretar na sua identificação.

Marisa, Mário e Jorge, denominados assim ficticiamente, atuam no Poder Judiciário, há 2 , 8 e 5 anos, respectivamente. Marisa atua nas Varas da Infância, da Família e Criminal. Mário atua na Vara da Infância e Juventude e Jorge nas Varas da Família e da Infância. Carlos é psicólogo na polícia civil há três anos. Sua atuação ocorre numa delegacia especializada, onde atende crianças vítimas de abuso sexual praticado por adolescentes. Paula, psicóloga do Ministério Público há um ano e dois meses, trabalha com projetos. Ela não atende diretamente ao usuário do serviço. A última entrevistada, Carol, é psicóloga da Defensoria Pública há 11 meses e atende ao público que busca auxílio na Defensoria.

Dentre os seis participantes, somente Marisa não possui nenhuma pós-graduação e Carol é a única que possui pós-graduação em Psicologia jurídica. Nenhum dos entrevistados tem o título de especialista na área. Todos são servidores públicos, admitidos para os cargos por meio de concurso público.

\section{Instrumentos e cuidados éticos}

O instrumento consistiu numa entrevista semiestruturada. As questões abordaram temas pertinentes à atuação profissional dos participantes, suas atividades diárias, momentos frustrantes e gratificantes que têm no trabalho, possíveis conflitos éticos que enfrentavam nas suas atuações, como percebiam a relação entre eles e a clientela e a relação entre a Psicologia e o direito, quais orientações consideravam importantes para um psicólogo na área jurídica, entre outras.
As entrevistas foram realizadas mediante gravação em áudio e as falas foram transcritas minuciosamente de forma a obter-se registros mais fidedignos possíveis. Porém, como já dito, informações que pudessem identificar os participantes foram omitidas ou alteradas quando transcritas para este artigo.

Os locais para realização das entrevistas foram escolhidos de modo a facilitar a locomoção dos participantes. Com exceção da psicóloga do Poder Judiciário, que foi entrevistada em uma universidade federal, e da psicóloga do Ministério Público, cuja entrevista deu-se no CRP de sua atuação, os quatro outros tiveram a entrevista realizada em seus locais de trabalho. Todas as salas possibilitaram a realização da entrevista de forma reservada e privativa. Os cuidados éticos foram rigorosamente observados e seguidos conforme orientação do Comitê de Ética em Pesquisa (Resolução no 196/96 do Conselho Nacional de Saúde), o qual aprovou a realização deste estudo.

Os participantes foram informados quanto à atuação, na área da Psicologia jurídica, da pesquisadora que os entrevistou. Notou-se que, durante as entrevistas, eles trouxeram algumas expressões sem a preocupação de explicá-las, afinal pressupunham que a entrevistadora tinha conhecimento de determinados termos, ou seja, que ela participava da mesma comunidade discursiva que eles. Contudo, ressalta-se que, tal relação não comprometeu os resultados da pesquisa, pois o método da AID leva em consideração a implicação do pesquisador na configuração da cena enunciativa $^{3}$. Além do mais, as entrevistas foram analisadas por um grupo de pesquisadores em análise institucional do discurso da Universidade Federal do Paraná - do qual faz parte a entrevistadora - cujos demais membros não atuavam na área de Psicologia jurídica e nem possuíam qualquer relação com os participantes da pesquisa.

A análise dos discursos foi feita a partir do objetivo do estudo maior, identificando no discurso de psicólogos que atuam no sistema de justiça, como se configura a Psicologia jurídica em suas práticas. Mais especificamente, para os objetivos deste artigo, o olhar das pesquisadoras voltou-se para algo que surpreendeu nas análises: as cenas discursivas em que os participantes traziam uma prática delineada por instrumentalizar o sistema de justiça com uma suposta verdade. Tal verdade seria descoberta pelo psicólogo jurídico por meio de técnicas próprias de sua ciência.

${ }^{3}$ Ao dialogar com Maingueneau, Guirado (2000) utiliza-se do termo cena enunciativa como sendo o discurso. Ela é o contexto em que a fala é produzida e do qual fazem parte os atores e as regras de enunciação. 
Assim, uma "justiça cega" seria auxiliada pelos olhos que enxergam do psicólogo; um olhar, configurado pelos entrevistados, como sendo "clínico".

Ressalta-se que o tema escolhido para este artigo é apenas um recorte da análise, dentre outros recortes possíveis. Deste modo, o que será apresentado nos resultados focou nesse aspecto dos discursos dos participantes, não como hipótese que se buscou confirmar na investigação, mas sim como algo que, a partir dela, pode-se evidenciar. Convidamos, pois, o leitor a apreciar o movimento analítico que se desenhou.

\section{Resultados}

A tensão entre o que se espera que se diga e o que se pode dizer marca o cotidiano da atuação dos entrevistados. Por suposto, espera-se que o psicólogo busque/ desvende uma verdade relativa ao fato investigado, a qual deverá ser publicada no documento (relatório e/ou parecer), endereçado ao operador do direito. Tal tarefa, todavia, não é isenta de conflitos: a quem privilegiar? O sistema impessoal da justiça? Ou a pessoa, e sua privacidade, que narra o fato em questão? O extrato abaixo ilustra o embate:

Pesquisadora: E existem conflitos éticos na atuação de um psicólogo jurídico?

Marisa: [...] Às vezes a gente fica muito preocupada porque a gente faz a entrevista com a pessoa aí ela já pergunta: ah, o que eu falei ninguém vai ler né? Aí você explica pra pessoa né. Então até que ponto você pode colocar o que a pessoa te falou, porque muitas vezes eles tão achando que é só pra gente, aí você esclarece, mas daí será que a pessoa vai te contar tudo!?

Pesquisadora: E como você procura lidar com esse conflito ético?

Marisa: Eu tento colocar as informações essenciais. É... muitas vezes a gente acaba omitindo informações. Aí você pensa né, isso talvez poderia, digamos, prejudicar a pessoa. Se for relevante tento colocar de uma outra maneira. Ou se percebo que já têm outros, é, é, subsídios ali, digamos, pra embasar a minha conclusão, que não vai prejudicar o processo em si, eu tento não colocar.
No discurso de Marisa, vemos que o usuário pode deixar de contar tudo ao psicólogo se este profissional lhe der esclarecimentos. Caso Marisa explique à pessoa atendida por ela sobre a publicidade daquilo que esta contará, pode ser que tal pessoa omita o que Marisa precisaria saber. Ao buscar descobrir tais informações íntimas o psicólogo explica à pessoa, parcialmente, quem terá acesso às informações, encenando com este um jogo de esconde-esconde. O psicólogo esconde informações da pessoa atendida para que ela revele a ele certas informações, ou seja, para que lhe conte "tudo". O "tudo" parece ser trazido no discurso dessa participante como sendo uma verdade que se busca descobrir na relação psicólogo-usuário. Uma verdade seria tudo o que almeja o psicólogo jurídico? A decisão sobre o que deve ser dito caberia à psicóloga. Há uma preocupação reconhecida em seu discurso, onde ela tem que escolher entre "prejudicar o processo" ou "prejudicar a pessoa".

Aquele a quem a psicóloga atende pode ser visto no primeiro extrato como sendo, explicitamente, o sistema de justiça pois, para que a pessoa "conte tudo", alguns esclarecimentos precisam ser omitidos. Portanto, o cliente do psicólogo é o sistema de justiça, que obterá as verdades fornecidas pelo profissional. Porém, no segundo extrato, observa-se que ela omite informações para não prejudicar a pessoa. Há um conflito de interesses: ao mesmo tempo que deve ser dada uma resposta ao sistema de justiça, deve-se omitir informações. Porém, ao final, numa tentativa de conciliação no dizer, a participante afirma não colocar informações contanto que o processo não seja prejudicado.

No discurso de Marisa há uma distinção de lugares entre pessoa e processo, como se estivessem em lados opostos, numa arena onde se digladiam e, ao final, sairá um vencedor. Alguém sempre sairá prejudicado! A verdade aparece como elemento decisivo nesta cena; quando ela é evidenciada, pelo psicólogo, um dos dois perde. Na batalha travada, o psicólogo decide, julgando, como um juiz, já que a verdade está em suas mãos, quem será vitorioso. A arma utilizada - pelo processo e pela pessoa - seria a aptidão para esconder. Quem melhor esconde fica menos propenso a perdas. Assim, esconder/descobrir uma pretensa verdade é o que está em jogo nesta cena.

No discurso de Jorge também se apresenta um cenário de batalha, conforme segue:

Porque se tu perde a neutralidade tu te cega, enfim. E isso facilita, particularmente nesse trabalho aqui 
que tu, que tu tem partes brigando, vamos dizer assim. E que essa briga é projetada sobre ti porque tu é quem vai dar o parecer contra um ou contra outro. Então de antemão eles não sabem, né, a tua, qual vai ser o lado que tu vai ir, vamos dizer assim. Ainda que a gente não vá, não tome partido né.

Ao mesmo tempo em que Jorge fala da imagem do psicólogo jurídico dotado de uma importante neutralidade, cuja perda desta ocasionaria cegueira, ele discorre sobre a possibilidade de tomar "partido", "ainda que" possa não o tomar. Sendo assim, não é condição sine qua non de sua prática atuar de forma neutra. Mas, se perder a neutralidade, fica cego! Ele indica que existe um partido que poderia ser tomado nesta trama, fazendo-nos pensar que há um lado da verdade para o qual o psicólogo "vai ir", mesmo o usuário não sabendo qual é.

Há partes brigando e cabe ao psicólogo, com seu parecer, posicionar-se de um lado. Então, quando seu parecer vai "contra um ou contra outro", ficaria ele cego em sua atuação. Há, portanto, momentos de cegueira na prática deste psicólogo. A clientela do psicólogo jurídico se faz em meio à escolha (uma escolha feita por um cego) de quem ele privilegiará. Ou seja, o cliente é aquele que será privilegiado com o parecer do psicólogo. Assim, constrói-se a imagem de um profissional que tem que escolher, cegamente, uma das partes, e, nesse cenário, tem que delimitar quem é seu cliente: o sistema de justiça ou o usuário.

Outro participante também mostra incerteza quanto a sua clientela, quando lhe perguntado sobre quem seria ela, como veremos:

Pois é (risos). Tá bom. O termo que a gente costuma usar aqui pra clientela, embora eu questione um pouco isso, mas de fato é o termo usual que a gente tem aqui, são das pessoas que buscam o judiciário. Eu tendo a ver a clientela como o Estado, na verdade. Porque afinal de contas eu sou um servidor do Estado que estou cumprindo determinações judiciais. Assim, então, pra ser mais exato meu cliente seria o juízo; e a juíza que determina um trabalho meu e é pra ela que eu entrego esse trabalho de novo. Mas isso acaba se perdendo, essas questões técnicas acabam se perdendo aqui no tumulto do nosso dia a dia. Frequentemente nós usamos cliente pra designar essas pessoas que nós não chamamos de pacientes, porque não é uma relação terapêutica, afinal de contas. Então quando você me fala de clientela imediatamente me vem isso à mente. Nesse sentido, a clientela seriam essas pessoas que procuram o tribunal, seja as pessoas que procuram o tribunal ou as pessoas a quem o tribunal procura (Mário).

Mário afirma que sua clientela é o Estado, afinal serve a este. Nota-se que ele conjuga na mesma frase duas instâncias: Estado e judiciário, tendo ele que servir ao Estado e, concomitantemente, cumprir o que é determinado pelo judiciário. Logo servir ao Estado é cumprir o que o juiz determina. Mas mesmo ele afirmando ser esta sua clientela, outras vozes aparecem em seu discurso quando ele diz que mais alguém, com ele - a gente -, usa o termo clientela para se referir às pessoas que buscam o judiciário.

Mário diferencia os termos cliente e paciente, excluindo o último de sua prática, a qual não se dá num contexto terapêutico. Infere-se que há um resgate, por Mário, da Psicologia clínica, campo tradicional da terapia, para, então, retirá-la do contexto em que ele atua. Afinal, há nomenclatura própria na Psicologia jurídica. Nota-se um campo de tensão entre as duas áreas de atuação do psicólogo, terapêutica e jurídica, no discurso deste participante. Ele nega o uso de termo que seria próprio da relação terapêutica e traz à cena àquele que reitera a relação estabelecida neste contexto, legitimando com isso a prática do psicólogo num campo específico, mesmo havendo dificuldade de delimitar a clientela em meio ao "tumulto". Então fica-nos a dúvida de qual cenário poderia este profissional delimitar a quem atender, senão o dia a dia?

Abaixo, notamos de que modo o psicólogo consegue ter acesso às situações em sua relação com o usuário:

A exigência que a gente tem aqui de olhar pra uma situação e enxergar bem aquela situação, de tu tentar de alguma forma enxergar com clareza o que realmente tá acontecendo, né. [...] pra conseguir no final fazer um quadro claro disso e com fundamento e com consistência pra poder, digamos, dar um encaminhamento bom pra situação, né. [...] pra ajudar ela a enxergar o que eu tô enxergando, que talvez seja uma coisa positiva pra ela poder ver aquilo que eu tô vendo. Eu não sei se tu entendeu o que eu quis dizer? Até porque a gente tem todo um manejo de trato com as pessoas, pra elas de alguma forma receberem melhor o que tu tem pra dizer, inclusive sendo contrário a elas, né (Jorge). 
Exigem de Jorge, em sua prática, "enxergar com clareza" as situações para fazer um quadro claro delas e, só assim, ele poderia dar bom encaminhamento, pressupondo o entrevistado que há um alcance objetivo sobre o que "realmente" acontece e que ele pode enxergar isso. Para ele, cabe ao psicólogo "ajudar" as pessoas a enxergarem o que ele viu, o que seria positivo a elas. Tal ação é possível, conforme vemos no discurso, porque há um "manejo" da Psicologia ao tratar pessoas; com isso ela (a Psicologia) dá conta de fazer com que as pessoas recebam melhor até mesmo aquilo que lhes é contrário a seu interesse. Supõe-se tratar de uma prática de convencimento, por parte do psicólogo, à pessoa atendida; convencimento de que até mesmo aquilo que vai contra ela pode, no "dizer" do psicólogo, ser recebido e aceito. Há uma imagem de psicólogo jurídico, neste discurso, em que o ato de enxergar enaltece o profissional. Diferencia-se dos demais aquele que enxerga bem, pois consegue ajudar e, mais, convencer pessoas, pois acessa a realidade. Como diz o ditado: "em terra de cegos quem tem olho é rei!".

Em outro momento, Jorge especifica o tipo de olhar que o faz enxergar, afirmando que "Tu tem que ter um olhar clínico. Tu tem que tentar enxergar o que aquela criança tá vivendo né. [...]”. Assim, vemos um profissional capaz de enxergar o que o outro está vivendo. Para tal, o psicólogo tem que ter um "olhar clínico". Com isso, ele sobrepõe tal forma de ver, apontando que uma visão do campo clínico seria superior e, portanto, necessário o uso dela para a atuação no campo jurídico. Esta forma de olhar aparece associada à capacidade de enxergar a vida do outro em acontecimento. A Psicologia clínica aqui apresenta-se dotada de qualidades que poderiam contribuir para o trabalho do psicólogo neste campo de atuação. Para alcançar o que precisa, enxergar o que o outro "tá vivendo", o psicólogo deveria remeter-se ao seu conhecimento clínico, não sendo suficiente o conhecimento da Psicologia jurídica. Aqui configura uma Psicologia jurídica que, com o psicólogo lançando mão de um olhar clínico, poderia ter acesso a uma pretensa verdade; verdade esta que parece estar ligada à vivência do outro. Portanto, acessar o que o outro vive, ou seja, suas verdades, é possível por meio do olhar clínico.

$\mathrm{O}$ acesso à realidade/vida do outro, pelo psicólogo, é tema recorrente nos discursos dos participantes. Ao falar sobre um momento frustrante, Carol nos diz:
[...] A gente fez a avaliação da avó, favorável a essa guarda da avó, tudo, conseguindo que fosse incluído na certidão de nascimento o nome do pai, que não tava e tal, entregamos a avaliação pro defensor e o defensor não usou a avaliação, disse que não precisava, e a avó não conseguiu a guarda. Então assim, isso frustra muito a gente, sabe. Porque a gente sabe, a gente foi lá na casa, a gente fez um trabalho, assim, de um mês pra gente levantar todas as informações que a gente precisava, elaborou o documento, entregou na mão do defensor e o defensor não usou. Então assim, aqui dentro do órgão a gente sente resistência. E ele, eu acho no meu entender que ele achou que se ele levasse isso pra juíza ia ser como uma afronta à equipe dela, sabe, porque a equipe disse que não e nós dissemos que sim. Então seria uma afronta. Então assim, devagarinho a gente tá construindo nosso espaço, sabe, mas é bem complicado.

Vê-se no discurso de Carol que ela se frustra quando o operador do direito, aqui o defensor público, não faz uso do trabalho realizado por ela, ou seja, do "documento" que ela produziu. Ela aponta que seu trabalho teria a condição de mudar o destino de uma pessoa, porém o defensor não usou a avaliação que a psicóloga realizou e a avó não conseguiu a guarda que pleiteava judicialmente. Ainda, ela mostra que havia outra equipe, a qual se colocou contra ela. Notamos uma Psicologia jurídica composta por "equipes", que disputam entre si a detenção da verdade sobre as pessoas. Enquanto a equipe da juíza, tinha uma verdade, a equipe da defensoria pública documentou outra verdade, mesmo Carol tendo acessado, em um mês, "todas" as informações.

A especificidade no olhar do psicólogo, que acessaria àquilo que outros não conseguem, aparece no discurso de Paula, quando fala de um momento gratificante:

São momentos em que eu consigo atender a uma solicitação, são momentos em que eu consigo trazer uma outra, uma outra ótica pra, pra, pra pessoas assim que eu vejo que tem um olhar mais conservador em algumas questões, situações em que eu consigo, junto com pessoas de outras áreas, solucionar problemas sociais, né, ou então encaminhar soluções pra problemas sociais.

A participante fala sobre se sentir gratificada ao atender solicitações. Tal atendimento relaciona-se em 
conseguir olhar de forma diferente, trazendo tal olhar às pessoas que possuem uma forma mais conservadora. O olhar - não conservador - da participante permite que ela consiga solucionar problemas sociais. Assim, Paula traz para a cena um psicólogo que, com um olhar diferenciado dentro do sistema de justiça, enxerga a solução dos problemas e, por isso, soluciona-os. Aqui aparece, mais uma vez, um sistema de justiça que é auxiliado a enxergar os fatos com os olhos do psicólogo.

Algo sensorial, que não é explicitamente o enxergar, é relacionado à atuação do psicólogo no discurso de Marisa, como veremos abaixo:

Eu percebo que, muitas vezes, senão na maioria das vezes, é o nosso relatório que é decisivo assim pros processos. [...]. Eu vejo que o direito é muito racional. Mas a gente como psicóloga consegue perceber certas coisas que pra eles passariam despercebidas.

Para ela, o psicólogo "percebe" aquilo que para o direito passaria despercebido, devido ao caráter "racional" deste último. Infere-se, aqui, que a racionalidade seria um impasse para tal percepção. Portanto, a Psicologia parece não ser racional, o que lhe permite ter percepções. Sendo a Psicologia, diferente do direito - racional - traria no documento psicológico - relatório -, decisivo para os processos, elementos irracionais? As verdades descobertas pela percepção do psicólogo são mostradas à justiça no relatório. $\mathrm{O}$ documento psicológico, deste modo, faz o operador do direito acessar "certas coisas" que não seriam possíveis de serem acessadas, senão pela percepção do psicólogo.

Carlos também nos mostra um psicólogo colaborador com o direito. Vejamos:

Eu acredito que a criança tem que ter um lugar pra que ela possa se expressar como ela queira se expressar. E alguém, não vou dizer agora o próprio psicólogo, mas alguém capacitado de ter ouvido pra poder ouvi-la e entendê-la. Daí sim, aí mostrar pro juiz do que que ele precisa. Vamos falar assim. [...] Eu digo pra você, a criança fala, você escuta e mostra pro jurídico, para o direito, o que essa criança quis trazer. Nós tamos falando de abordagens diferentes, totalmente diferentes; a abordagem do direito e a abordagem da Psicologia.

Para Carlos, o psicólogo teria um ouvido, supostamente especial, com o qual ouve e entende a criança, atributo este do qual o operador do direito não dispõe. Com esta capacidade caberia ao psicólogo "mostrar" o que precisa o juiz e, mais, "mostrar" ao direito o que a criança "quis" trazer. Portanto, seria atribuição do psicólogo "mostrar" para o operador do direito o que há além do dito, afinal não vale somente aquilo que o operador escuta e/ ou vê, pois seu acesso limitado não lhe permite acessar o que não foi dito pela criança. Há um lugar junto ao psicólogo para o usuário se expressar e, enquanto faz isso, o psicólogo apreende o que ele fala e o que ele não fala, inclusive. Além de uma capacidade de escuta diferenciada, o psicólogo, no discurso desse participante, é aquele que escuta o que "quis" o usuário trazer, mas não trouxe. Com isso, ele é capaz de "mostrar" para a justiça, aparentemente cega, aquilo que ela não pôde ver, afinal a abordagem da justiça difere da abordagem da Psicologia.

Quando a verdade da Psicologia não é considerada pelo operador do direito, o psicólogo mostra-se frustrado, como aparece no extrato abaixo:

O que eu menos gosto? Nesse momento é a resistência que, que a gente encontra de diversos profissionais, não só da equipe técnica do Tribunal, mas até dos próprios advogados quando a gente se coloca um pouco, sabe. Até os defensores, às vezes, não têm aquela coisa assim/ não nos veem como uma ferramenta que pode ser usada e que tem uma ação efetiva, sabe. Eu já trabalhei com defensores que eu era totalmente dispensável. Então isso me chateia um pouco, que a gente tem que tar a todo momento brigando e demonstrando que a Psicologia é uma ferramenta que pode ser usada e que vai trazer muitos benefícios, né (Carol).

A participante mostra uma resistência do operador do direito em dar-lhe crédito, mesmo tendo a Psicologia capacidade de ações efetivas. Carol resiste à condição de ser dispensável, denotando, com isso, um psicólogo jurídico útil como instrumento de trabalho ao operador do direito, como uma possível ferramenta de acesso à verdade.

A cegueira necessária para decidir por um lado na briga, portanto a escolha feita por um cego e, uma escolha (ou não escolha), em condições tumultuadas, trouxeram elementos sobre como estes psicólogos delimitam sua clientela. Quando se acredita em um lado na trama processual, pressupõe-se a existência de uma verdade. Ao descobrir a verdade, o psicólogo conta 
(a verdade), em seu relatório, à justiça, que é cega, não tendo ela olhos para enxergar a verdade. E é buscando, e manuseando, essa verdade que a Psicologia jurídica configura sua prática no sistema de justiça.

Um direcionamento oculto sobre a demanda é recorrente nas falas dos participantes. Algo que não está posto e que, portanto, precisa ser enxergado, percebido pelo profissional de Psicologia é o que desvelaria a o que está encoberto. Além disso, há atribuições de qualidades ao profissional de Psicologia, aparentemente inatas, as quais não fazem parte do rol de atributos do operador do direito. Ao psicólogo jurídico seria demandada uma visão - para "enxergar bem" -, uma percepção - para "perceber" o que é despercebido -, sabedoria - para saber do que precisam as pessoas. O "dizer" do psicólogo teria a capacidade de convencimento. Tais atributos remetem-nos a uma certa onipotência deste profissional, que empoderado teria uma missão salvacionista. Estaria o psicólogo, no campo jurídico, salvando um sistema de justiça deficiente? A cegueira deste seria compensada com o olhar clínico do psicólogo?

\section{Discussão}

A busca pela verdade, como prática dos psicólogos no sistema de justiça, mostrada nos discursos dos participantes dessa pesquisa, revelou que estes profissionais enfrentam conflitos cotidianos em suas atuações quando se lançam a tal atividade. Os discursos que compõem a demanda do psicólogo nesse campo, empurra-o a diversas práticas, ora da inquirição, ora do exame, e no final, da produção de provas periciais que comprovem fatos. No mesmo cenário, este profissional ainda precisa se haver com o que compete à sua própria disciplina, a Psicologia (Ortiz, 2012). Aí é que os dilemas borbulham.

Essa prática híbrida do psicólogo na justiça confunde-o quanto a quem deve atender, não conseguindo, ele, delimitar sua clientela: ora compreendendo ser o usuário atendido, ora ser o operador do direito, solicitante do atendimento. Surge em meio a este tema, um resgate da Psicologia clínica para demarcar que a pessoa atendida pelo psicólogo não seria o paciente, da clínica, mas, sim, o cliente, da Psicologia jurídica.

A tensão, vista nos discursos, impera quando o tema é a investigação da veracidade de fatos pelo psicólogo, não raras vezes, aludindo-se à Psicologia clínica para discorrer sobre tal. Rovinski (2007b) afirma que, cabe ao psicólogo, nesse contexto, lançar mão de estratégias diferentes daquelas usadas na clínica, a fim de garantir maior confiabilidade das informações obtidas nos atendimentos. Os modelos conceituais da Psicologia clínica não podem ser utilizados no âmbito jurídico, devendo-se buscar novos modelos para produção de conhecimento no contexto das leis. Como ponto principal para tal distinção ela cita o foco da avaliação que, na clínica deve ser o mundo interno do paciente, enquanto que, no âmbito jurídico deve-se ater às demandas do judiciário; os achados clínicos, durante a avaliação forense, devem ser associados àquilo que é de interesse do sistema de justiça. Ainda, ela salienta que se deve ter cuidado para não transformar o processo de avaliação em um processo terapêutico (Rovinski, 2011). Portanto, para esta a autora, a clientela do psicólogo jurídico seria o sistema de justiça, afinal suas demandas é que precisam ser respondidas pelo profissional. Já na clínica, o cliente é a pessoa atendida, e a demanda está relacionada aos pedidos deste. Porém, em ambos o mundo interno da pessoa atendida é o objeto de trabalho do psicólogo, que é quem acessa-o.

Diferentemente da autora acima, há questionamentos quanto ao trabalho realizado por psicólogos no campo da justiça (Arantes, 2007; Brito, 2012; Ortiz; 2012), uma vez que este profissional vem sendo designado a atuar de maneira conflitante com sua formação profissional. Como exemplo, temos a já citada prática do Depoimento sem Dano, na qual é considerada, em primeiro lugar, a necessidade do processo. Demandas e desejos do sujeito inquirido, neste caso, a criança, não são o que orienta o trabalho do psicólogo, como nos ensina Arantes (2007). Este, ao exercer a Psicologia, deveria considerar erros, fantasias, lapsos, esquecimentos, pausas, sonhos, silêncios e contradições do sujeito que fala. Todos esses elementos são opostos à "verdade verdadeira dos fatos" (2007, p. 13) (aspas da autora), a qual é o anseio do sistema de justiça. Com isso a autora questiona a possibilidade da Psicologia instrumentalizar a justiça com verdades, dando-nos a entender que esta não seria sua clientela.

Para Brito (2012), a avaliação psicológica demandada pelo sistema de justiça não pode, de forma alguma, ser equiparada a uma investigação, já que aquela deve se utilizar somente de técnicas psicológicas para a coleta de dados (entrevistas, testes, observações, dinâmicas de grupo, escuta e intervenções verbais), conforme preconiza a Resolução CFP n 007/2003. 
Sendo assim, lançar suspeitas contra quem está sendo atendido, a fim de verificar a veracidade de sua fala, é uma tarefa própria de outras categorias profissionais, que não a do psicólogo. Este deve sempre considerar, conforme a citada resolução, durante um processo de avaliação psicológica, que as questões de ordem psicológica, as quais, por sua vez, são somente as que devem interessar ao psicólogo, possuem "determinações históricas, sociais, econômicas e políticas, sendo elas elementos constitutivos no processo de subjetivação" (2003, p. 4). Assim, não havendo um objeto de estudo estático, mas, sim, que se configura a todo momento em suas relações, conforme entendimento do CFP, não há possibilidade do psicólogo encontrar uma verdade sobre determinado fato.

Configurou-se, nas entrevistas, um psicólogo atuando no sistema de justiça sem clara delimitação de sua clientela. A definição da AID, usada neste texto, dá-se a partir da concepção de que a clientela é formada por "atores cujas relações sociais são objeto da ação institucional" (Albuquerque, 1978, p. 74). Tomando a Psicologia jurídica como instituição, isto é, como uma prática que, ao se repetir cotidianamente, torna-se legítima, é necessário definir quem são os indivíduos cujas relações, com a Psicologia jurídica no contexto da justiça, são objeto de sua ação institucional. Ao buscar delimitar sua clientela, os psicólogos entrevistados remeteram-se a uma prática relacionada à descoberta de verdades. Eles justificavam a escolha de sua clientela discorrendo sobre questões acerca do sigilo profissional e sobre a quem deveriam entregar as informações que obtinham/ descobriam sobre os fatos/verdades. Dessa forma, a ação desses profissionais volta-se à descoberta de verdades sobre a pessoa atendida e, mais, caberia a eles decidir a quem dar tal verdade, da qual somente eles dispunham. Portanto, o objeto da Psicologia jurídica seria a verdade. Apenas tendo a posse exclusiva de um objeto, uma instituição se define como tal. Por ele é que a instituição reivindica monopólio de propriedade, havendo permanente processo de apropriação deste objeto e, em contrapartida, de desapropriação dele de outras instituições, isto é, de tornar ilegítimo o saber de outros sobre este objeto (Albuquerque, 1978).

Ao reivindicar o monopólio da verdade, psicólogos, no sistema de justiça, como vimos nos discursos, disputam-na, negando a possibilidade do operador do direito de acessá-la diretamente. Isso fica evidente quando os participantes da pesquisa falam sobre a impotência que o operador jurídico teria, por ser mais racional, por não enxergar coisas que os psicólogos enxergam e mais, por necessitar, que os psicólogos lhe digam, por meio dos relatórios/laudos, a decisão que deve ser tomada. Portanto, um psicólogo que enxerga bem, fazendo uso do olhar clínico, é detentor do objeto tão ansiado pelo cego sistema de justiça: a verdade!

\section{Considerações finais}

As questões que levaram a esta pesquisa foram pensadas a partir da prática de uma das pesquisadoras como psicóloga do sistema de justiça. As solicitações de trabalho, as quais a angustiavam e confundiam, eram imaginadas como demanda somente dos operadores do direito. Conflitos sobre a finalidade e, mais, sobre a quem deveria servir com seu trabalho, marcavam a sua prática cotidiana. Com este estudo não se pretendeu fazer generalizações e nem confirmar ou refutar hipóteses, afinal o resultado a que se chegou diz respeito aos discursos de uma amostra restrita de psicólogos que atuam no sistema de justiça, lotados em apenas dois estados do nosso país. Sendo assim, outras configurações da prática do psicólogo no sistema de justiça poderiam ser encontradas (ou não).

Esperamos ter situado o leitor, a partir de uma análise, dentre outras possíveis, de como vem se configurando a Psicologia jurídica, nas práticas dos psicólogos na justiça. O recorte operado acerca da atuação em prol da descoberta de pretensas verdades, sendo tema recorrente nos discursos dos participantes da pesquisa, evidenciou-nos um profissional que se constitui em meio a conflitos quanto a quem seu trabalho deve servir: ao sistema de justiça ou à pessoa atendida? Tal confusão acerca da clientela nos mostrou, ainda, um embate deste psicólogo, entre aquilo que imagina ser a Psicologia jurídica e o que imagina ser a Psicologia clínica. Portanto, vimos que quando o sistema de justiça era posto como sendo sua clientela, este profissional se legitimava como psicólogo jurídico, porém, quando a clientela era a pessoa atendida, àquela a quem ele deveria dar respostas - dar a verdade -, ele estaria se colocando como psicólogo clínico. Com isso, encontramos duas psicologias que se superpõem e, às vezes, não se complementam. Há uma naturalização: a separação entre pessoas que demandam o serviço e são entrevistadas pelos psicólogos e pessoas que demandam, formalmente, a verdade do psicólogo (os operadores do direito e o próprio psicólogo). Os entrevistados não reconhecem que todos esses compõem a 
instituição, que todos fazem parte do jogo e que a ação de um afeta a ação de outro.

A verdade apareceu como sendo o objeto pelo qual a Psicologia jurídica busca deter o monopólio para legitimar-se como instituição. Há o pressuposto de um profissional que credita a si a condição de ter maior acesso a uma verdade para além dos fatos; seria algo que não se vê, mas que o psicólogo jurídico poderia ver, e a ferramenta da qual dispõe para isso seria o olhar clínico, o qual não foi definido, em momento algum, nas entrevistas.

Para a surpresa das pesquisadoras, ao contrário do que se supôs no início dessa pesquisa - o desvelamento de verdades ser uma demanda somente do operador do direito ao psicólogo -, apareceu nas entrevistas uma Psicologia que também anseia e acredita na possibilidade dela mesma descobrir verdades no trabalho realizado no âmbito da justiça. Isso se evidenciou mais ainda quando buscava para si a posse dessa verdade, negando a possibilidade de acesso direto a ela pelo operador do direito. Somente com a ajuda e pelo olhar do psicólogo é que o sistema de justiça enxergaria a verdade. Mas, mais do que isso, o olhar clínico é que auxiliaria à cega justiça. E, assim, a Psicologia jurídica anseia seu status de instituição, repetindo práticas (na atuação cotidiana dos psicólogos), reivindicando o monopólio de um objeto (a verdade) e buscando delimitar sua clientela.

\section{Referências}

Albuquerque, J. A. G. (1978). Metáforas da desordem. Rio de Janeiro, RJ: Paz e Terra.

Altoé, S. (2003). Atualidade da psicologia jurídica. In R. Bastos (Org.), Psicologia, microrrupturas e subjetividades (pp. 11-124). Rio de Janeiro, RJ: E-papers.

Alves, E. O., \& Saraiva, J. E. M. (2009). O que pode a fala de uma criança no contexto judiciário? In Conselho Federal de Psicologia - CFP. (Org.), Falando sério sobre a escuta de crianças e adolescentes envolvidos em situação de violência e a rede de proteção: Propostas do Conselho Federal de Psicologia-Brasília (pp. 101-112). Brasília, DF: CFP.

Ambrosio, G. (2010). Psicologia do testemunho. Revista de Direito Econômico e Socioambiental, 1(2), 395-407.

Arantes, E. M. M. (2016). Duas décadas e meia de vigência da Convenção sobre os Direitos da Criança: Algumas considerações . In E. P. Brandão (Org.), Atualidades em psicologia jurídica (pp. 53-96). Rio de Janeiro, RJ: Nau.

Arantes, E. M. M. (2007). Mediante quais práticas a Psicologia e o Direito pretendem discutir a relação? Anotações sobre o mal estar. de http://www.aasptjsp.org.br/sites/default/files/arquivos-artigos38-1285183711.pdf.

Arantes, E. M. M. (2009). Pensando a proteção integral: Contribuições ao debate sobre as propostas de inquirição judicial de crianças e adolescentes como vítimas ou testemunhas de crimes. In Conselho Federal de PsicologiaCFP. (Org.), Falando sério sobre a escuta de crianças e adolescentes envolvidos em situação de violência e a rede de proteção: Propostas do Conselho Federal de Psicologia- Brasília (pp. 79-98). Brasília, DF: CFP.

Batista, A. P., \& Cadan, D. (2017). Testemunho de crianças em conflitos conjugais: o limiar entre a obrigação e o direito de expressão. In A. P. Batista, \& J. Medeiros (Orgs.), Psicologia e polícia: Diálogos possíveis (pp. 51-68). Curitiba, PR: Juruá.

Brasil. (2007). Ministério da Justiça Departamento Penitenciário Nacional - DEPEN Diretrizes para atuação e formação dos psicólogos do sistema prisional brasileiro. Brasília, DF: Ministério da Justiça.

Brito, L. M. T. (2012). Anotações sobre a psicologia jurídica. Psicologia Ciência e Profissão, 32(num esp.), 194-205. https:// doi.org/10.1590/S1414-98932012000500014

Brito, L. M. T. (2012). Das avaliações técnicas aos depoimentos infanto-juvenis: novos rumos dos casos de suspeita de abuso sexual. In L. M. T. Brito (Org.), Escuta de crianças e de adolescentes: Reflexões, sentidos e práticas (pp. 51- 84). Rio de Janeiro, RJ: EDUERJ.

Felix, L. F., \& Pergher, G. K. (2010). Memória em julgamento: Técnicas de entrevista para minimizar as falsas memórias. In. L. M. Stein (Ed.), Falsas memórias: Fundamentos científicos e suas aplicações clínicas e jurídicas (pp. 209227). Porto Alegre, RS: Artmed.

Foucault, M. (2005). A arqueologia do saber (7a ed.). Rio de Janeiro, RJ: Forense Universitária.

Froner, J. P.,\& Ramires, V. R. R. (2008). Escuta de crianças vítimas de abuso sexual no âmbito jurídico: uma revisão crítica da literatura. Paidéia, 18(40), 267-278. https:// doi.org/10.1590/S0103-863X2008000200005 
Galvão, L. F., \& Serrano, C. E. G. (2007). Análise de discurso, leitura institucional: Um método. In R. Lerner, \& M. Guirado (Orgs.), Psicologia, pesquisa e clínica: Por uma análise institucional do discurso (pp. 21-36). São Paulo, SP: Annablume.

Guirado, M. (2010). A análise institucional do discurso como analítica da subjetividade. São Paulo, SP: Annablume.

Guirado, M. (2000). A clínica psicanalítica na sombra do discurso: Diálogos com aulas de Dominique Maingueneau. São Paulo, SP: Casa do Psicólogo.

Guirado, M. (2009). O exercício da psicologia como instituição. Interação em Psicologia, 13(2), 323-333.

Guirado, M. (1997). Vértices da pesquisa em psicologia clínica. Psicologia USP, 8(1), 143-155. https://doi. org/10.1590/S0103-65641997000100009

Ortiz, M. C. M. (2012). A Constituição do perito psicólogo em varas de família à luz da análise institucional do discurso. Psicologia: Ciência e Profissão, 32(4), 894-909. httpS://doi.org/10.1590/S1414-98932012000400010

Paulino, M. (2009). Abusadores sexuais de crianças: A verdade escondida. Estoril: Prime Books.

Resolução CFP no 007/2003. (2003). Institui o manual de Elaboração de Documentos Escritos produzidos pelo psicólogo, decorrentes de avaliação psicológica, e revoga a Resolução CFP no 17/2002. Brasília, DF: Conselho Federal de Psilocologia.

Resolução CFP $n^{o}$ 010/2010. (2010). Institui a regulamentação da Escuta Psicológica de Crianças e Adolescentes envolvidos em situação de violência, na Rede de Proteção. Brasília, DF: Conselho Federal de Psilocologia.

Resolução CFP no 012/2011. (2011). Regulamenta a atuação da(o) psicóloga(o) no âmbito do sistema prisional. Brasília, DF: Conselho Federal de Psilocologia.

Rovinski, S. L. R. (2007b). Fundamentos da perícia psicológica forense (2a ed). São Paulo, SP: Vetor.

Rovinski, S. L. R. (2007a). Perícia psicológica na área forense. In J. A. Cunha (Org.), Psicodiagnóstico-V (5a ed., pp. 183-195). Porto Alegre, RS: Artmed.

Rovinski, S. L. R. (2011). Avaliação psicológica no contexto jurídico. In Conselho Federal de Psicologia - CFP. (Org.), Ano da avaliação psicológica: Textos geradores (pp. 95-102). Brasília, DF: Conselho Federal de Psicologia.

Stein, L. M. (2009). Falsas memórias: Fundamentos científicos e suas aplicações clínicas e jurídicas. Porto Alegre, RS: Artmed.

Danielle Cadan

Mestre em Psicologia pela Universidade Federal do Paraná. Curitiba - PR. Brasil.

E-mail: danipsi_ca@hotmail.com

Luciana Albanese

Doutora em Psicologia Escolar e do Desenvolvimento Humano pela Universidade de São Paulo. São Paulo - SP. Brasil.

E-mail: lu5valore@gmail.com

Endereço para envio de correspondência:

Rua Expedicionário Carlos Costa, 160- apto 103. Dom Bosco. Cep: 88.307-220. Itajaí/SC. Brasil.

Recebido 29/08/2017

Reformulado 14/11/2017

Aprovado 12/01/2018

Received 08/29/2017

Reformulated $11 / 14 / 2017$

Approved 01/12/2018 
Recibido 29/08/2017

Reformulado 14/11/2017

Aceptado 12/01/2018

Como citar: Cadan, D., \& Albanese, L. (2018). Um olhar clínico para uma justiça cega: Uma análise do discurso de psicólogos do sistema de justiça. Psicologia: Ciência e Profissão, 38(2), 316-331. https://doi.org/10.1590/1982-3703003582017

How to cite: Cadan, D., \& Albanese, L. (2018). A clinical view of a blind justice: An analysis of the discourse of psychologists from the justice system. Psicologia: Ciência e Profissão, 38(2), 316-331. https://doi.org/10.1590/1982-3703003582017

Cómo citar: Cadan, D., \& Albanese, L. (2018). Una mirada clínica para una justicia ciega: Un análisis del discurso de psicólogos del sistema de justicia. Psicologia: Ciência e Profissão, 38(2), 316-331. https://doi.org/10.1590/1982-3703003582017 